\title{
The well-being of playful adults: Adult playfulness, subjective well-being, physical well-being, and the pursuit of enjoyable activities
}

\author{
Proyer, Rene T
}

\begin{abstract}
It was hypothesized that playfulness in adults relates positively to different indicators of subjective but also physical well-being. A sample of 255 adults completed subjective measures of playfulness along with self-ratings for different facets of well-being and the endorsement to enjoyable activities. Adult playfulness demonstrated robust positive relations with life satisfaction and an inclination to enjoyable activities and an active way of life. There were also minor positive relations with physical fitness. Leading an active way of life partially mediated the relation between playfulness and life satisfaction. The study provides further evidence on the contribution of adult playfulness to different aspects of well-being.
\end{abstract}

Posted at the Zurich Open Repository and Archive, University of Zurich

ZORA URL: https://doi.org/10.5167/uzh-78008

Journal Article

Published Version

Originally published at:

Proyer, Rene T (2013). The well-being of playful adults: Adult playfulness, subjective well-being, physical well-being, and the pursuit of enjoyable activities. European Journal of Humour Research, 1(1):84-98. 


\title{
The well-being of playful adults: Adult playfulness, subjective well-being, physical well-being, and the pursuit of enjoyable activities
}

\author{
René T. Proyer \\ University of Zurich, Switzerland
}

\begin{abstract}
It was hypothesized that playfulness in adults relates positively to different indicators of subjective but also physical well-being. A sample of 255 adults completed subjective measures of playfulness along with self-ratings for different facets of well-being and the endorsement to enjoyable activities. Adult playfulness demonstrated robust positive relations with life satisfaction and an inclination to enjoyable activities and an active way of life. There were also minor positive relations with physical fitness. Leading an active way of life partially mediated the relation between playfulness and life satisfaction. The study provides further evidence on the contribution of adult playfulness to different aspects of well-being.
\end{abstract}

Keywords adult playfulness, enjoyable activities, health behaviour, life satisfaction, physical fitness, playfulness

According to Barnett (2007), playfulness is defined as "the predisposition to frame (or reframe) a situation in such a way as to provide oneself (and possibly others) with amusement, humour, and/or entertainment" (2007: 955; see also Barnett 1990, 1991ab, 2012). She also lists a set of adjectives describing the nature of playfulness further. Some of these descriptors (e.g., cheerful, happy, or outgoing) characterize greater levels of subjective wellbeing, while others such as being active and dynamic point towards physical well-being and activity. This has also been reflected in other studies on the structure of playfulness. For example, Proyer (2012a) examined the dimensionality of playfulness in a lexical study based on implicit linguistic and psychological theories (derived from a corpus analysis). He identified seven basic factors; namely, (1) cheerful-engaged; (2) whimsical; (3) impulsive; (4) intellectual-charming; (5) imaginative; (6) light-hearted; and (7) kind-loving. The opencheerful factor comprises contents reflecting subjective but also physical well-being (e.g., being cheerful, high levels of positive mood, or being energetic). 
The theoretical framework of this study is the health behaviour model (Kubzansky et al. 2009; Vollrath et al. 1999; Wiebe \& Smith 1997). This model suggests that personality can have an impact on the physical well-being of people via an effect on the compliance with health-oriented behaviours (see Kubzansky et al. 2009; Wiebe \& Smith 1997; Vollrath et al. 1999). Using this model, an impact of personality on health-promoting and damaging activities but also, more generally speaking, on health-oriented behaviours has been demonstrated. It is proposed that greater levels of playfulness can also have such effects. For example, greater levels of energy, which have been identified as characteristics of playful adults (e.g., Barnett 2007, 2011; Proyer 2012a) can facilitate physical activity. This, in turn, is expected to have an impact on different facets of physical well-being.

The present study addresses various indicators of psychological but also self-assessed physical well-being allowing for a better understanding of the contribution of playfulness to these dimensions. Several aspects of well-being are being differentiated in this study. Indicators for subjective well-being were (a) a general rating for the current psychological status; and (b) life satisfaction as its cognitive component. Physical well-being was addressed by (a) a general rating for the current health status; (b) specific health behaviours (e.g., pursuing an active way of life; hygiene, or eating behaviors); and (c) subjective ratings for physical fitness (strength, cardio-respiratory fitness, flexibility, and coordination skills). Hence, physical well-being in this study is operationalised as the pursuit of health-oriented behaviours and greater levels of physical fitness (in self-ratings). Along with these variables, the endorsement to enjoyable activities was tested as a further indicator of overall well-being. A greater endorsement to enjoyable activities has been shown to have a positive impact on physical well-being (see Pressman et al. 2009). It should be noted that enjoyable activities should not be used synonymously with playful activities. Greater levels of activity and vitality have been related to playfulness (Barnett, 2007; Proyer \& Ruch 2011) but it is argued that not each enjoyable activity must necessarily have a playful component and vice versa. Therefore, it seems fruitful to study the overlap between the playful and enjoyable of activities.

As in Proyer and Ruch (2011) and Proyer (2012c), playfulness has been assessed via a short instrument for overall playfulness (in the sense of an easy onset and high intensity of playful experiences along with the frequent display of playful activities; Proyer 2012b) and by means of Glynn and Webster's Adult Playfulness Scale (1992; APS). The latter allows differentiating five facets of playfulness (i.e., spontaneous, expressive, fun, creative, and silly). These instruments enable the examination of global playfulness but also different facets. This provides a differentiated picture of the nature of the relations.

\section{Subjective well-being and playfulness.}

Earlier studies have shown that playfulness in adults has robust relations with outcome variables such as intrinsic motivation (e.g., Amabile et al. 1994), creativity and spontaneity (e.g., Barnett 2007; Glynn \& Webster 1992), positive attitudes towards the workplace or job satisfaction (Yu et al. 2007), or academic achievement (Proyer 2011) to name but a few. In Proyer (2012c), life-satisfaction correlated with $r=.31(p<.001)$ and $r=.18(p<.05)$ with fun-oriented and creative variants of playfulness. Barnett (2007) identified "cheerful" and "happy" as two components, which people relate to playfulness in adults. Furthermore, playfulness has been associated with greater quality of life (Proyer \& Ruch 2010), flowexperiences (Csikszentmihalyi 1975), or the pleasurable and engaged life (Proyer 2012c). The latter are two key components of Seligman's (2002) authentic happiness theory describing distinct yet not incongruent routes towards well-being; one of them being associated with hedonism, the other one with flow-experiences. Proyer \& Ruch (2011) studied playfulness in 
relation with the "good character;" i.e., strengths of character as morally positively valued traits (Peterson \& Seligman 2004). Findings suggested that playfulness relates to higher intellectual (e.g., curiosity, creativity, or love of learning) and emotional strengths (e.g., zest, hope, love, or social intelligence) but lower strengths of restraint (e.g., self-regulation, persistence, perspective, or prudence). As expected, playfulness has been predicted best by the strengths of humour but also by low prudence, greater appreciation of beauty and excellence, creativity, and teamwork. Finally, Fredrickson $(1998,2001)$ argues that play and playfulness in adults may facilitate the experience of positive emotions. In terms of her broaden-and-built-theory of positive emotions, these cannot only broaden a person's current action-thought repertoire but also help building psychological resources.

In a study with adolescents (12 to 19 years), Staempfli (2007) found positive relations between playfulness and psychological as well as physical health (self-ratings). Playful adolescents engaged in higher levels of leisure activities and demonstrated greater leisure satisfaction (which was related to psychological health). Playfulness correlated positively with different coping styles (active, internal, withdrawal). Additionally, it was shown that higher playful students endorsed leisure to seek companionship and enhance mood through leisure (Qian \& Yarnal 2011) and that playful people do not experience boredom in their leisure time and are aware of opportunities of what to do in their leisure time (Barnett 2011). Based on the literature reported, a positive relation between feeling psychologically well and greater life-satisfaction and playfulness was expected.

\section{Physical well-being and playfulness.}

It was expected that playful adults perceive themselves as physically healthy (cf. Staempfli 2007). This seems to be further substantiated by Proyer (2012c), who found that playfulness relates to the satisfaction of intrinsic life goals with health being one of them.

Beyond a general self-evaluation of the health status, the Questionnaire of Multiple Health Behavior (Wiesmann et al. 2003) was used in this study for being able to comment on different types of health behavior. This measure provides scores on the overall health behavior and on six aspects of health-behaviors; i.e., an active way of life, compliance, substance avoidance, security orientation, diet, and hygiene. Based on broader descriptions of the playfulness trait (e.g., Barnett 1990, 1991ab, 2007; Glynn \& Webster 1992; Lieberman 1977; Proyer 2012a) one might assume that greater playfulness relates to greater levels of activity (e.g., exploratory behaviour, more frequent time spent in the nature, etc.). However, there are also variants of playfulness for which negative relations were expected. The sillyform of playfulness relates to low conscientiousness (Proyer 2012c), lower inclinations to self-regulation (Proyer \& Ruch 2011) and, presumably, even less careful behaviour in general. Hence, health-related aspects such as the avoidance of potentially enjoyable but also harmful substances (e.g., alcohol, nicotine), restrained eating behaviour, or displaying a strong security orientation was expected to be negatively related with playfulness (see also O'Connell et al. 2000).

It was further expected that playfulness also relates to greater levels of physical fitness. In children, physical spontaneity (e.g., in the sense of coordinated movements) has been identified as one of the core components of playfulness (e.g., Barnett 1991a; Lieberman 1977; Singer et al. 1980). It has already been argued that play and playfulness can trigger positive emotions; e.g., joy enhances the likelihood of playful behaviours to occur. According to Fredrickson $(1998,2001)$ positive emotions can be helpful in facilitating physical resources such as coordination, strength, or cardiovascular health. While greater playfulness was expected to concur with indicators of physical fitness, these relations were expected to be 
numerically lower than those for subjective well-being.

Enjoyable activities and playfulness.

Manell (1984) argues that playful people enjoy leisure activities. This is also in line with Barnett (2011), who found that playful adults were less prone to experiencing boredom in their leisure time. In Proyer (2012c), playfulness was associated with the endorsement of pleasurable (hedonistic) orientations. It was expected that playfulness correlates positively with a greater propensity to enjoyable activities.

Enjoyable activities were assessed by means of the Pittsburgh Enjoyable Activities Test (PEAT; Pressman et al. 2009). Research using the PEAT showed that the endorsement of enjoyable activities relates to physiological parameters (such as lower blood pressure, total cortisol) but also physical fitness (lower waist circumference, body mass index), the selfperception of greater physical fitness, but also psychological variables such as lower depression or negative affect (Pressman et al. 2009). Similar relations were expected for playfulness (and its variants).

Aims of the present study.

The main aim of the present study was examining the relations between different facets of playfulness in adults and various indicators of well-being and the propensity to enjoyable activities.

\section{Method}

\section{Sample}

The sample consisted of 255 adults between 18 and 67 years $(M=29.2, S D=9.1)$. About two thirds $(n=167)$ were women. More than half were in a partnership or being married $(n=133)$ and $n=112$ were single. More than one third held a degree from a university or a university of applied sciences $(n=94)$.

\section{Instruments}

The Short Measure of Adult Playfulness (SMAP; Proyer 2012b) is a five-item questionnaire for the assessment of playfulness in adults in the sense of an easy onset and high intensity of playful experiences along with the frequent display of playful activities. A sample item is "I am a playful person." All items are positively keyed and answers are given on a 4-point scale (1= "strongly disagree," 4 = "strongly agree"). Proyer reports a one-dimensional solution for the SMAP (in exploratory and confirmatory factor analyses) and high internal consistencies ( $\geq .80$ in different samples; it was .88 in this sample). There were positive relations in the expected range with the need for play-scale (Jackson 1984), Glynn and Webster's (1992, 1993) Adult Playfulness Scale, and a total score for Barnett's (2007) descriptors for playfulness. Support for the divergent validity was found in negative relations with the seriousness scale of the State-Trait-Cheerfulness Inventory (Ruch et al. 1996). High and low scorers in the SMAP differed in the expected way in ratings for approval and disapproval for high and low structured workplaces and abstract vs. non-abstract pieces of art (Proyer 2012b). Several further studies support the validity of the instrument (Proyer 2012c; Proyer \& Ruch 2011). 
The Adult Playfulness Scale (APS; Glynn \& Webster 1992, 1993) consists of 32 adjectives, of which twenty-five are being scored. It contains five scales; i.e., spontaneous (e.g., spontaneous vs. disciplined, impulsive vs. diligent; $\alpha=.77$ in this sample), expressive (e.g., bouncy vs. staid, open vs. reserved; $\alpha=.74$ ), fun (e.g., bright vs. dull, excitable vs. serene; $\alpha=.69$ ), creative (e.g., imaginative vs. unimaginative, active vs. passive; $\alpha=.70$ ), and silly (e.g., childlike vs. mature, whimsical vs. practical; $\alpha=.69$ ). Answers are given on a 7-point rating scale. Glynn and Webster (1992) report satisfying internal consistencies and test-retest correlations, and a robust factor solution. The APS has been used widely in research (e.g., Amabile et al. 1994; Bozionelos \& Bozionelos 1999). As in Proyer (2011, 2012abc) and Proyer and Ruch (2011), the German version of the scale has been used.

The Pittsburgh Enjoyable Activities Test (PEAT; Pressman et al. 2009) is a subjective measure for the "frequency of engagement in a spectrum of enjoyable activities that could be done alone or with others, in an array of locations, and [...] both active and inactive" (Pressman et al. 2009: 727). The scale consists of ten activities (i.e., spending quiet time alone; spending time unwinding; visiting others; eating with others; doing fun things with others; club, fellowship, and religious group participation; vacationing; communing with nature; sports; and hobbies). The PEAT utilizes a five-point scale for indicating whether the person has in the last month, "never" to "every day" pursued each of the activities. A German translation of the activities has been used in this study. The alpha-coefficient in this sample was .61, which reflects the heterogeneity of the activities and is in the range of what has been reported by Pressman et al. (i.e., .65 to .72).

The Questionnaire of Multiple Health Behaviour (MHB-39; Wiesmann et al. 2003) assesses habitual health-related behaviour in 39 domains (each assessed by a single item; e.g., "use of dental floss," or "eating sweets"). Answers are given on a 5-point scale ( $1=$ "never," 5 = "always"). Wiesmann et al. provide data on good psychometric properties (in terms of high reliabilities for the total score) and support for the validity of the instrument. The MHB39 has been used in several other studies ever since its publication (e.g., Wiesmann et al. 2011). Following Wiesmann et al.'s (2003) procedure, the 39 items were subjected to a principal component analysis. Six factors were extracted (explained variance $=40.73 \%$ ) and rotated to the Varimax-criterion. In accordance with Wiesmann and colleagues, the factors were labelled as active way of life (e.g., being active, doing subjectively meaningful things), compliance (e.g., taking care and complying to regulations in road traffic, being environmentally aware), substance avoidance (e.g., use of alcohol, nicotine), security orientation (e.g., practicing safe sex, getting vaccinations), diet (e.g., well-balanced eating, avoiding rich meals), and hygiene (e.g., regular dental, physical hygiene). The MHB-39 was analysed on the basis of the total score $(\alpha=.82)$ and at the level of the six factors.

The short form of the Physical Fitness Questionnaire (Bös et al. 2002) consists 12 items, assessing four basic motor abilities (i.e., cardio-respiratory fitness, strength, flexibility, and coordination). Each item represents a specific activity, which has to be rated on a 5-point scale ( 1 = "I'm not able to do this activity," 5 = "I can do this activity without difficulties"). Sample items are "do a somersault" (coordination), or "jog for an hour without a break" (cardio-respiratory fitness). Internal consistencies for the total scale was $\alpha=.80$ (cardiorespiratory fitness: $\alpha=.86$, strength: $\alpha=.75$, flexibility: $\alpha=.61$, and coordination: $\alpha=.53$ ).

The Satisfaction with Life Scale (SWLS; Diener et al. 1985) is a five-item measure for the assessment of life satisfaction (sample item: "The conditions of my life are excellent"). It utilises a 7-point Likert scale ( 1 = "strongly disagree," 7 = "strongly agree"). The German translation has proved its usefulness and good psychometric properties in earlier studies (e.g., Proyer et al. in press; Ruch et al. 2010). The alpha-coefficient in this sample was .82. 


\section{Procedure}

Participants completed the measures in an online survey that was hosted by the institution, where the study has been planned and conducted. Advertisements have been posted via leaflets at public transport stations, in online forums, and via email-lists. Upon request, participants received a feedback on their personal results sent to them via Email. They were not paid for their services. In the literature, collecting data in online-studies has been criticised (e.g., for possible biases of the collected samples). However, there is empirical evidence that data collected via the Internet is comparable to data collected in more conventional ways (e.g., Gosling et al. 2004).

\section{Results}

\section{Preliminary analyses.}

There were minor relations with demographics for some of the variables that entered the study. For example, overall playfulness (SMAP) decreased with higher age $(r(255)=-.18, p<$ $.01)$ and women reported better health behaviour (total score of the MHB-39) than men $(M=$ $3.53, S D=0.33$ vs. $M=3.29, S D=0.34 ; d=0.72$ ), while men exceeded women in all ratings on their physical fitness (e.g., coordination, $M=4.80, S D=0.49$ vs. $M=4.50, S D=0.61, d=$ $0.54)$ except for flexibility, were women scored higher $(M=3.31, S D=0.97$ vs. $M=3.92, S D$ $=0.91, d=0.65)$. Therefore, it was decided to control for demographics in the subsequently conducted analyses.

\section{Adult Playfulness and well-being.}

Playfulness and its facets were correlated with all indicators of psychological and physical well-being that entered the study. Additionally, a multiple correlation coefficient was computed between all components of the APS and the other variables for estimating the shared variance of playfulness with these variables. All correlation coefficients are given in Table 1.

Table 1. Partial Correlations (Controlling for Age and Sex) Between Playfulness and Indicators of Psychological and Physical Well-Being

\begin{tabular}{|c|c|c|c|c|c|c|c|c|}
\hline & SWLS & SMAP & $S P O$ & $E X P$ & FUN & $C R E$ & Silly & $R^{2}$ \\
\hline \multicolumn{9}{|l|}{ Status } \\
\hline Health & $.26^{* *}$ & .10 & .04 & -.06 & .13 & .06 & -.07 & .04 \\
\hline Psyche & $.34 * *$ & $.19 * *$ & .08 & .03 & $.29 * *$ & $.15^{*}$ & .00 & .10 \\
\hline SWLS & -- & $.20 * *$ & $.17 * *$ & $.14^{*}$ & $.43 * *$ & $.23 * *$ & -.04 & .21 \\
\hline \multicolumn{9}{|l|}{ МHB-39 } \\
\hline Total & $.33 * *$ & .01 & -.03 & .11 & $.30 * *$ & $.30 * *$ & $-.26 * *$ & .22 \\
\hline AWOL & $.35 * *$ & $.22 * *$ & $.30 * *$ & $.39 * *$ & $.46 * *$ & $.45^{* *}$ & .04 & .28 \\
\hline SA & .01 & $-.16^{*}$ & $-.24 * *$ & $-.15^{*}$ & -.03 & .03 & $-.21 * *$ & .08 \\
\hline COM & $.15^{*}$ & -.03 & -.08 & .09 & .11 & .05 & $-.16^{*}$ & .08 \\
\hline HYG & .11 & $-.13 *$ & $-.17 * *$ & .02 & .05 & $.16^{*}$ & $-.23 * *$ & .11 \\
\hline SEC & .10 & -.07 & $-.13 * *$ & $-.22 * *$ & -.07 & $-.13 *$ & $-.26 * *$ & .11 \\
\hline DIET & $.20 * *$ & -.01 & .00 & -.06 & $.17 * *$ & $.17 *$ & $-.18 * *$ & .11 \\
\hline$P F Q$ & & & & & & & & \\
\hline
\end{tabular}




\begin{tabular}{lllllllll} 
Strength & $.19 * *$ & .07 & .08 & .04 & .11 & $.15^{*}$ & .04 & .03 \\
CRF & $.18^{* *}$ & .09 & $.12^{*}$ & .10 & $.20^{* *}$ & $.19^{* *}$ & .05 & .05 \\
Flexibility & .13 & -.04 & .04 & .10 & .09 & .12 & .01 & .02 \\
COR & .10 & $.18^{* *}$ & .08 & .00 & $.14 *$ & .05 & .12 & .05 \\
Total & $.21 * *$ & .08 & .11 & .10 & $.20^{* *}$ & $.19 * *$ & .06 & .05 \\
\hline
\end{tabular}

Note. $N=255$. Status = Single item measure for self-evaluated health ("How would you rate your current overall health condition") and psychological status ("How would you rate your current overall psychological condition") on a 10-point scale ( $1=$ very bad, $10=$ excellent $)$; SWLS = Satisfaction With Life Scale; SMAP = Short Measure of Adult Playfulness; facets of Adult Playfulness Scale: SPO = spontaneous, EXP = expressive, $\mathrm{CRE}=$ creative variants of playfulness (of the Adult Playfulness Scale); MHB-39 = Multiple Health Behavior, $\mathrm{AWOL}=$ Active Way of Life; $\mathrm{SA}=$ Substance Avoidance; $\mathrm{COM}=$ Compliance; $\mathrm{HYG}=$ Hygiene; $\mathrm{SEC}=$ Security Orientation; PFQ = Physical Fitness Questionnaire: Strength, Cardio-respiratory fitness (CRF), Flexibility, and coordination (COR); $R^{2}=$ multiple correlation coefficient between the five scales of the Adult Playfulness Scale and variable.

Table 1 shows that overall playfulness existed independently from subjective ratings of feeling healthy. A better self-rated psychological status corresponded with greater playfulness in terms of an easy onset and high intensity of playful experiences along with the frequent display of playful activities but also with fun-oriented and creative playfulness. Better healthratings as well as psychological status correlated with greater life satisfaction.

Overall playfulness (SMAP) yielded positive relations with an active way of life and negative relations with substance avoidance and hygiene. The five APS facets shared $22 \%$ of the variance with multiple health behaviours (total score of MHB-39; multiple correlation coefficient). The APS yielded $28 \%$ overlapping variance with an active way of life; all scales were positively correlated with this facet of health-behaviour (between 9 and $21 \%$ shared variance) except for the silly-variants of playfulness (zero-correlation). Fun and creative variants of playfulness correlated positively with dietary behaviour (i.e., refraining from sweets and high fat meals) and silly-variants demonstrated negative relations. For the total score of health-behaviour, greater fun and creative variants of playfulness were positively and its silly-forms were negatively related with health-behaviours.

For a final evaluation of these relations, a hierarchical multiple regression analysis with playfulness as criterion (the SMAP total score as global indicator of playfulness) and the MHB-39 facet-scores as predictors (entered in step 2, stepwise; step $1=$ age and gender, enter), yielded a multiple correlation coefficient of $R^{2}=.13, F(4,255)=8.99, p<.001$. In the final model, an active way of life $\left(\beta=.27, p<.001, \Delta R^{2}=.07\right)$ and substance avoidance $(\beta=$ $.16, p<.05, \Delta R^{2}=.02$ ) were significant predictors. Age and gender accounted for an additional $\Delta R^{2}=.04$.

Adult playfulness correlated positively with life satisfaction; numerically largest relations were found for the fun-variants of playfulness. The five subscales of the APS accounted for $21 \%$ of the variance in life-satisfaction (multiple correlation coefficient). Pursuing an active way of life and compliance were positively related to life satisfaction. Leading an active way of life was identified as the component with the comparatively strongest relations with playfulness (e.g., if using the multiple squared correlation coefficient of the APS facets or the regression analysis with the SMAP as indicator). Therefore, it was further tested whether this component would also partially mediate the relation between playfulness and life satisfaction. The mediator analysis was performed using the bootstrapping approach recommended by Preacher and Hayes $(2004,2008)$ with 5,000 bootstrap resamples. Estimates were computed in a simple mediation model for direct $\left(\mathrm{c}^{\prime}\right.$; playfulness $\rightarrow$ life satisfaction), indirect ( $\mathrm{a} \times \mathrm{b}$; $\mathrm{a}=$ playfulness $\rightarrow$ active way of life [AWOL] and $\mathrm{b}=\mathrm{AWOL} \rightarrow$ life satisfaction), and total effects $\left(\mathrm{c} ; \mathrm{c}=\mathrm{c}^{\prime}+\mathrm{a} \times \mathrm{b}\right)$. There was $\mathrm{a}$ 
significant total effect $(\mathrm{c}=.277)$ and the mediation analysis suggested that the relation between playfulness and life satisfaction was partially mediated by an active way of life $\left(\mathrm{c}^{\prime}=\right.$ $.171 ; \mathrm{a}=.0328, \mathrm{~b}=.321)$. The confidence interval for the indirect pathway $(99 \%)$ was between .026 and .198 (confidence intervals that do not include 0 indicate significant effects) and the partial mediation accounted for about $11 \%$ of the relationship.

Self-assessed health existed widely independently from overall playfulness with the exception of greater coordination skills. The numerically highest relations were found between overall physical fitness and fun and creative variants of playfulness; the latter were also related to greater cardio-respiratory fitness. Again, a hierarchical linear regression was computed (criterion = overall playfulness, SMAP) and predictors were the four facets of the Physical Fitness Questionnaire; they were entered in step 2 (stepwise) after age and gender in step 1 (enter). There was a significant squared multiple correlation coefficient of $R^{2}=.06$, $F(3,255)=4.61, p<.01$. In the final model, greater coordination skills $\left(\beta=.13 p<.05, \Delta R^{2}\right.$ $=.02)$ and demographics $\left(\Delta R^{2}=.04\right)$ were significant predictors. Of course, these coefficients were small in size, yet they suggest that playfulness as a personality trait can have an impact on the physical status of a person (at least in self-assessments).

\section{Adult playfulness and enjoyable activities.}

The pursuit of enjoyable activities was correlated with overall playfulness and the different facets of playfulness. As mentioned earlier, the Pittsburgh Enjoyable Activities Test covers heterogeneous activities and, therefore, an analysis separately for the single activities has been conducted. Correlation coefficients (controlled for age and gender) are given in Table 2.

Table 2. Partial Correlations (Controlled for Age and Gender) between Enjoyable Activities Covered in the PEAT and Indicators of Life Satisfaction and Playfulness.

\begin{tabular}{|c|c|c|c|c|c|c|c|c|}
\hline PEAT & $S W L S$ & $S M A P$ & $S P O$ & $E X P$ & FUN & $C R E$ & Silly & $R^{2}$ \\
\hline Total & $.19^{* *}$ & $.21 * *$ & $.21 * *$ & $.25 * *$ & $.40 * *$ & $.31 * *$ & .06 & .17 \\
\hline \multicolumn{9}{|l|}{ Scales } \\
\hline 1 & $-.15^{*}$ & -.11 & $-.21 * *$ & $-.16^{*}$ & $-.17 * *$ & -.10 & $-.13^{*}$ & .05 \\
\hline 2 & .05 & .03 & -.02 & .05 & .02 & .06 & -.01 & .01 \\
\hline 3 & $.16^{* *}$ & .10 & $.15^{*}$ & $.17 * *$ & $.29 * *$ & $.19 * *$ & .04 & .09 \\
\hline 4 & .08 & .02 & .03 & .09 & $.16^{*}$ & $.14^{*}$ & .01 & .03 \\
\hline 5 & $.27 * *$ & $.30 * *$ & $.39 * *$ & $.34 * *$ & $.49 * *$ & $.31 * *$ & $.24 * *$ & .26 \\
\hline 6 & .03 & $.20 * *$ & .07 & .07 & $.18 * *$ & .06 & .03 & .04 \\
\hline 7 & $.21 * *$ & .07 & $.13 *$ & .08 & $.20 * *$ & .11 & .06 & .04 \\
\hline 8 & $.24 * *$ & $.19 * *$ & $.26 * *$ & $.29 * *$ & $.36 * *$ & $.27 * *$ & .06 & .16 \\
\hline 9 & .10 & .05 & .12 & $.18^{* *}$ & $.20 * *$ & $.25 * *$ & -.04 & .08 \\
\hline 10 & .10 & $.22 * *$ & $.16^{*}$ & .12 & $.29 * *$ & $.25 * *$ & .10 & .10 \\
\hline
\end{tabular}

Note. $N=252$. PEAT $=$ Pittsburgh Enjoyable Activities Test; activities covered are spending quiet time alone (1); spending time unwinding (2); visiting others (3); eating with others (4); doing fun things with others (5); club, fellowship, and religious group participation (6); going for a vacation (7); communing with nature (8); sports (9); and hobbies (10). SWLS = Satisfaction With Life Scale. SMAP = Short Measure of Adult Playfulness; facets of Adult Playfulness Scale: SPO = spontaneous, EXP = expressive, CRE = creative variants of playfulness (of the Adult Playfulness Scale). $R^{2}=$ multiple correlation coefficient between the five scales of the Adult Playfulness Scale and activity from PEAT.

$* p<.05 ; * * p<.01$.

Table 2 shows that greater overall playfulness correlated positively with doing fun-things 
with friends, pursuing one's hobby, engaging oneself in a club, fellowship, and religious groups and communing with nature. In terms of the multiple correlation coefficient (all APS subscales and the respective activity), doing joyful things with friends, being in the nature, and pursuing hobbies yielded the numerically largest coefficients (all $\geq 10 \%$ shared variance). Spending quiet time alone was negatively related to playfulness. Taking consciously time for relaxing at the end of a day existed unrelated from playfulness. Overall, fun-oriented playfulness demonstrated the numerically largest relations with the different indicators in the PEAT. Its silly-variants were widely unrelated from these activities with the exception of low inclination to spend quiet time alone and a greater endorsement of doing funny things with others. Here, of course, the question of an overlap in the measurement emerges; the funaspect in both measures (as a variant of playfulness and as a component of enjoyable activities) could lead to an over-estimation of this relation. Visiting others, doing fun things with others, vacationing, and communing in nature demonstrated robust relations with life satisfaction while a greater endorsement of spending quiet time alone yielded negative associations.

Using the ten PEAT-activities as predictors in a hierarchical multiple regression analysis (step 2, stepwise; step $1=$ demographics, enter) for predicting overall playfulness (SMAP, criterion) revealed a multiple squared correlation coefficient of $R^{2}=.15, F(4,255)=$ $10.37, p<.001$. In the final model, doing fun things with others $\left(\beta=.28 p<.001, \Delta R^{2}=.09\right)$, club, fellowship, and religious group participation $\left(\beta=.14 p<.05, \Delta R^{2}=.02\right)$ and the demographics $\left(\Delta R^{2}=.04\right)$ were significant predictors.

\section{Discussion}

The main aim of the present study was describing how playfulness in adults relates to physical and psychological well-being as well as the pursuit of enjoyable activities. The findings are encouraging in the sense of support for a positive association between playfulness and different indicators of well-being. The relations of playfulness with life satisfaction, the cognitive aspect of subjective well-being, replicated earlier findings well (Proyer 2012c). Overall playfulness in the sense of an easy onset and high intensity of playful experiences along with the frequent display of playful activities $(S M A P)$ as well as four out of the five facets of the Adult Playfulness Scale (APS) demonstrated positive relations with life satisfaction $\left(r^{2}\right.$ was between .03 and .18). Of course, not all of these were of practical relevance but some could be interpreted in more depth. The numerically largest relation was found for the fun-variants of playfulness (e.g., bright, excitable). This component might be closest to the experience of positive emotions (cf. Fredrickson 1998, 2001; Seligman 2011).

A further interesting finding of this study was that leading an active way of life partially mediated (about 11\%) of the relation between playfulness and life satisfaction. Hence, there seems to be an interesting interaction between physical activity and vitality and the relation between a person's level of playfulness and satisfaction with life. This helps for a better understanding of the psychological dynamics underlying this relation. Future research should test in more depth what types of activities and what facets of vitality play a role here.

There seems to be a mutual relation between playfulness and subjective well-being, which was also reflected in greater self-ratings of the current psychological state. This lends support to the notion that it may be fruitful to further explore the potential of playfulnessbased interventions for increasing the subjective well-being. Especially, what facets of playfulness are associated with what types of well-being. Proyer (2012a) argued that there could be facets of adult playfulness, which have not yet been studied with much attention. 
Therefore, a closer evaluation at the level of single facets is needed for a better understanding of these relations.

Furthermore, intervention studies are helpful to understand potential effects of an increase of playfulness on well-being. The 7-humour-habits program by McGhee (2010) has its foundations in seeing the sense of humor as a special variant of play, the play with ideas. Many of the elements of this program deal with playfulness (e.g., the creation of wordplays), or, more generally speaking, with the rediscovery of one's playfulness. There is evidence of the effectiveness of this program for increasing well-being and alleviating depression (Crawford \& Caltabiano 2011; Gander et al. in press; Proyer et al. in press; for an overview see Ruch et al. 2011). However, research in positive interventions has suggested that interventions focusing on deliberate activities aimed at increasing positive psychological functioning (e.g., positive emotions) are not only effective (Sin \& Lyubomirsky 2009) but can also be delivered in an economic way via online-settings (e.g., Gander et al. in press; Seligman et al. 2005). A research aim for future studies is testing whether playfulness-based interventions can be used in such settings as well and whether short-term interventions (e.g., practicing daily for one week) can lead to a sustainable increase in well-being as shown in Seligman et al. (2005; Proyer et al. in press).

The silly-variants of playfulness (e.g., childlike, whimsical) existed independently from life satisfaction and self-rated psychological status. One might argue that this is a rather heterogeneous category, which contains aspects that promote well-being, while others are aversive. Expressing this type of playfulness might also cause aversive reactions in others (e.g., indicating disapproval or misunderstanding of this type of behaviour), which may lead to negative feedbacks and hinder the emergence of positive relations. In Proyer (2012c), sillyvariants of playfulness correlated positively with enjoying to be laughed at (gelotophilia) but also enjoying laughing at others (katagelasticism; see Ruch \& Proyer 2009). The latter has been linked to aversive behaviour in the sense of bullying-type of behavior (Proyer, Neukom et al. 2012) but also psychopathic personality traits (Proyer, Flisch et al. 2012). One might argue that exceedingly expressing the silly-type of playfulness could entail crossing boundaries, which cause negative reactions on others and are, therefore, negatively evaluated by others. Overall, these findings support the notion of a plural nature of playfulness but not all of its facets are associated with subjective well-being. However, since only one specific aspect of subjective well-being has been tested in this study, the inclusion of different domains of satisfaction and other aspects of subjective well-being (e.g., positive and negative affect; see Barnett 2012) is warranted.

As expected, greater playfulness was related to specific types of health-oriented behaviour while others demonstrated negative relations. The five facets of the APS yielded between 8 (substance avoidance, compliance) and 28\% (active way of life) overlapping variance with the health-behaviours covered in the MHB-39. Especially, the pursuit of an active way of life demonstrated positive relations. Thus, greater activity in the sense of a positive health-oriented behaviour may be a prime characteristic of playful adults. It is argued that playful adults see many different options of what to do (see also Barnett 2011), which encourages greater levels of activity. However, not all forms of health-oriented behaviours were positively related with playfulness. Security orientation (e.g., safe sex, vaccinations), substance avoidance (e.g., avoiding alcoholic beverages, refraining from smoking), and dietary behaviour (e.g., well-balanced eating) demonstrated widely negative relations with playfulness. Proyer and Ruch (2011) found that strengths of restraint (e.g., self-regulation) from a broader set of positively valued personality traits (character strengths) were negatively related with playfulness, especially its silly-variants. Taken together with other findings such as lower expressions in Conscientiousness (Proyer 2012c), this may help explaining why 
aspects such as a well-balanced eating behavior get less endorsed with increasing playfulness. These findings also refer to a somewhat "darker side" of playfulness in the sense of problems that might be associated with extreme expressions of playful behavior (e.g., risk orientation). This encourages a more in-depth study of different types of risky behaviors and playfulness.

There were small yet sensible relations between self-assessed physical fitness and playfulness; the shared variance between the five facets of the APS and the different aspects of fitness was between 2 and 5\%. In the total score of the Physical Fitness Questionnaire and the subscale cardio-respiratory fitness (e.g., walking several steps without resting, jogging for 30 minutes), the numerically largest correlation coefficients were found for the fun- and creative variants of playfulness. Also, the overall playfulness (SMAP) demonstrated positive relations with coordination skills (e.g., standing on one foot without using the arms, jumping over a fence of one meter height). The self-rated physical status existed independently from the expression of playfulness. Of course, the correlation coefficients are not high and should not be over-interpreted-yet, it seems as if there is a tendency for greater playfulness to permeate into a better physical status. In the literature about playfulness in children, motor activity is frequently seen as an indicator of playfulness (see e.g., Lieberman 1977). Proyer (2012a) retrieved this also in written accounts on playfulness in the German language. One might argue that this could remain stable over time and translate into greater motor activity (e.g., in preferred leisure time activities) in adults.

In line with the expectations, playfulness was associated with the pursuit of enjoyable activities. Most of the variance, however, was accounted for by the activity of "doing fun things with others" (shared $26 \%$ of the variance with the five APS subscales) and "communing with nature" (16\%). The endorsements of "sports," "hobbies," and "visiting others" also yielded strong relations (8-10\%). Single correlation coefficients, however, were much larger; e.g., $r^{2}=.24$ between fun-variants of playfulness and "doing fun things with others." This relation, however, needs to be interpreted conservatively because of the obvious overlap in the measurement. The fun-component in both variables has an impact on the size of the correlation coefficient. Overall, physical activities, those directed at pursuing hobbies, and social activities demonstrated the comparatively largest relations. The latter was also supported by the finding that "spending quiet time alone" was negatively associated with playfulness (numerically smallest for spontaneous playfulness, $r=-.21$ ). This indicates that not all activities that are potentially enjoyable are also positively related to playfulness; or more specifically: to playfulness as operationalised in this study. Barnett (2007) or Proyer (2012a) describe structural assumptions that overlap partially with what has been measured here but identified also other components that have not been covered in this study. It is assumed that specific variants of playfulness (e.g., the imaginative, or more intellectual forms) can also be expressed in solitude, which may also lead to different relations with enjoyable activities. This, however, needs to be tested empirically. Additionally, the PEAT only covers a selected range of activities and it may be fruitful to study adult playfulness in its relation with a broader ranger of leisure activities to see in what areas playfulness is of greater or lesser relevance (see Barnett 2011; Quian \& Yarnal 2011). Furthermore, one might argue that the perceived function people assign to playfulness in various areas (e.g., leisure activities, at work, or in partnership) also has an impact on various facets of well-being. This also needs to be studied in more detail in future studies.

The study allows also discussing a few findings on life satisfaction. For example, life satisfaction was associated with both, greater self-rated physical and psychological status. Furthermore, it was positively related with overall health-related type of behaviours (primarily the active way of life). Also, better physical fitness was related to life satisfaction. The same was true for the pursuit of enjoyable activities, especially with "doing fun things 
with others," "communing with nature," "going for a vacation," and "visiting others"- as for playfulness "spending quality time alone" was negatively related with life satisfaction. However, not all of the enjoyable activities in the PEAT demonstrated positive relations with life satisfaction.

This study has several limitations. It is based on a community sample, which is not well-balanced in terms of age and gender. Therefore, replications with larger samples are warranted. Additionally, the operationalisation of playfulness and the indicators of subjective and physical well-being but also with the enjoyable activities can be criticized. For example, the theoretical foundation and psychometric properties of the Adult Playfulness Scale can be debated (e.g., Barnett 2007; Csikszentmihalyi 1975; Proyer 2012b). A further question relates to a possible overlap in the items themselves. For example, being active is an item for the assessment of the fun-variants of playfulness and the relations with leading an active way of life might be somewhat biased by the type of measurement. Again, this can be addressed by using different conceptualisations for playfulness in upcoming studies aimed at replicating and extending these findings (e.g., Barnett 2007; Proyer 2012a). Only specific facets of wellbeing and of enjoyable activities have been tested. The study only covers self-assessed physical fitness and this may be prone to several distortions. Further studies with additional measures but also different data sources (e.g., behavioural observations, peer reports, professional examination of the physical fitness, physiological data, etc.) and experimental approaches are encouraged.

\section{Notes}

* The author wishes to thank Fabian Gander, Nicole Jehle, and Sara Wellenzohn for their help with the preparation of the testing material and the data collection; and Tracey Platt for proofreading the manuscript.

** Correspondence concerning this article should be addressed to Dr. René Proyer, Department of Psychology, University of Zurich, Binzmühlestrasse 14/7, 8050 Zurich, Switzerland; E-mail: r.proyer@psychologie.uzh.ch

\section{References}

Amabile, T. M., Hill, K. G., Hennessey, B. A. \& Tighe, E. M. (1994). 'The Work Preference Inventory: Assessing intrinsic and extrinsic motivational orientations'. Journal of Personality and Social Psychology, 66, pp.950-967.

Barnett, L. A. (1990). 'Playfulness: Definition, design, and measurement'. Play and Culture, 3, pp.319-336.

Barnett, L. A. (1991a). 'The playful child: Measurement of a disposition to play'. Play and Culture, 4, pp.51-74.

Barnett, L. A. (1991b). 'Characterizing playfulness: correlates with individual attributes and personality traits'. Play and Culture, 4, pp.371-393.

Barnett, L. A. (2007). 'The nature of playfulness in young adults'. Personality and Individual Differences, 43, pp.949-958.

Barnett, L. A. (2011). 'How do playful people play? Gendered and racial leisure perspectives, motives, and preferences of college students'. Leisure Sciences, 33, pp.382-401.

Barnett, L. A. (2012). 'Playful People: Fun is in the mind of the beholder'. Imagination, Cognition and Personality, 31, pp.169-197.

Bös, K., Abel, T., Woll, A., Niemann, S., Tittlbach, S. \& Schott, N. (2002). 'Der Fragebogen zur Erfassung des motorischen Funktionsstatus (FFB-Mot) [The Physical Fitness Questionnaire 
(FFB-Mot)]'. Diagnostica, 48, pp.101-111.

Bozionelos, N. \& Bozionelos, G. (1999). 'Playfulness: Its relationship with instrumental and expressive traits'. Personality and Individual Differences, 4, pp.749-760.

Crawford, S. A. \& Caltabiano, N. (2011). Promoting emotional well-being through the use of humour. The Journal of Positive Psychology, 6, pp.237-252.

Csikszentmihalyi, M. (1975). 'Play and intrinsic rewards'. Journal of Humanistic Psychology, 15, pp.41-63.

Diener, E., Emmons, R. A., Larsen, R. J. \& Griffin, S. (1985). ,The Satisfaction with Life Scale'. Journal of Personality Assessment, 49, pp.71-75.

Fredrickson, B. L. (1998). 'What good are positive emotions?' Review of General Psychology, 2, pp.300-319.

Fredrickson, B. L. (2001). 'The role of positive emotions in positive psychology - the broaden-andbuild theory of positive emotions'. American Psychologist, 56, pp.218-226.

Gander, F., Proyer, R. T., Ruch, W. \& Wyss, T. (in press). 'Strength-based positive interventions: Further evidence on their potential for enhancing well-being and alleviating depression'. Journal of Happiness Studies.

Glynn, M. A. \& Webster, J. (1992). 'The Adult Playfulness Scale: An initial assessment'. Psychological Reports, 71, pp.83-103.

Glynn, M. A. \& Webster, J. (1993). 'Refining the nomological net of the Adult Playfulness Scale: Personality, motivational, and attitudinal correlates for highly intelligent adults'. Psychological Reports, 72, pp.1023-1026.

Gosling, S. D., Vazire, S., Srivastava, S. \& John, O. P. (2004). 'Should we trust web-based studies? A comparative analysis of six preconceptions about Internet questionnaires'. American Psychologist, 59, pp.93-104.

Jackson, D. N. (1984). Personality Research Form manual (3rd ed.). Port Huron, MI: Research Psychologists Press.

Kubzansky, L. D., Martin, L. T. \& Buka, S. L. (2009). 'Early manifestations of personality and adult health: A life course perspective'. Health Psychology, 28, pp.364-372.

Lieberman, N. J. (1977). Playfulness: Its relationship to imagination and creativity. New York, NY: Academic Press.

Mannell, R. (1984). 'Personality in leisure theory: The self-as-entertainment construct'. Society and Leisure, 7, pp.229-242.

McGhee, P. E. (2010). Humor as survival training for a stressed-out world: The 7 humor habits program. Bloomington, IN: AuthorHouse.

O’Connell, K., Gerkovich, M. M., Bott, M., Cook, M. R. \& Shiffman, S. (2000). 'Playfulness, arousalseeking and rebelliousness during smoking cessation'. Personality and Individual Differences, 29, pp.671-683.

Peterson, C. \& Seligman, M. E. P. (2004). Character strengths and virtues: A handbook and classification. Washington, DC: American Psychological Association.

Preacher, K. J. \& Hayes, A. F. (2004). 'SPSS and SAS procedures for estimating indirect effects in simple mediation models'. Behavior Research Methods, Instruments, and Computers, 36, pp.717-731.

Preacher, K. J. \& Hayes, A. F. (2008). 'Asymptotic and resampling strategies for assessing and comparing indirect effects in multiple mediator models'. Behavior Research Methods, 40, pp.879-891.

Pressman, S. D., Matthews, K. A., Cohen, S., Martire, L. M., Scheier, M., Baum, A., \& Schulz, R. (2009). 'Association of enjoyable leisure activities with psychological and physical well-being'. Psychosomatic Medicine, 71, pp.725-732.

Proyer, R. T. (2011). 'Being playful and smart? The relations of adult playfulness with psychometric and self-estimated intelligence and academic performance'. Learning and Individual Differences, 21, pp.463-467.

Proyer, R. T. (2012a). 'A psycho-linguistic study on adult playfulness: Its hierarchical structure and theoretical considerations'. Journal of Adult Development, 12, pp.141-149. 
Proyer, R. T. (2012b). 'Development and initial assessment of a short measure for adult playfulness: The SMAP'. Personality and Individual Differences, 53, pp.989-994.

Proyer, R. T. (2012c). 'Examining playfulness in adults: Testing its correlates with personality, positive psychological functioning, goal aspirations, and multi-methodically assessed ingenuity'. Psychological Test and Assessment Modeling, 54, pp.103-127.

Proyer, R. T., Flisch, R., Tschupp, S., Platt, T. \& Ruch, W. (2012). 'How does psychopathy relate to humor and laughter? Dispositions towards ridicule and being laughed at, the sense of humor, and psychopathic personality traits'. International Journal of Law and Psychiatry, 35, pp.263268.

Proyer, R. T., Neukom, M., Platt, T. \& Ruch, W. (2012). 'Assessing gelotophobia, gelotophilia, and katagelasticism in children: An initial study on how six to nine-year-olds deal with laughter and ridicule and how this relates to bullying and victimization'. Child Indicators Research, 5, pp.297-316.

Proyer, R. T. \& Ruch, W. (2011). 'The virtuousness of adult playfulness: The relation of playfulness with strengths of character'. Psychology of Well-Being: Theory, Research and Practice, 1:4.

Proyer, R. T., Ruch, W. \& Buschor, C. (in press). 'Testing strengths-based interventions: A preliminary study on the effectiveness of a program targeting curiosity, gratitude, hope, humor, and zest for enhancing life satisfaction'. Journal of Happiness Studies.

Proyer, R. T., Ruch, W. \& Müller, L. (2010). 'Sense of humor among the elderly: Findings with the German version of the SHS'. Zeitschrift für Gerontologie und Geriatrie, 43, pp.19-24.

Quian, X. L. \& Yarnal, C. (2011). 'The role of playfulness in the leisure stress-coping process among emerging adults: An SEM analysis'. Leisure/Loisir, 35, pp.191-209.

Ruch, W., Köhler, G. \& van Thriel, C. (1996). 'Assessing the "humorous temperament": Construction of the facet and standard trait forms of the State-Trait-Cheerfulness-Inventory - STCI'. Humor: International Journal of Humor Research, 9, pp.303-339.

Ruch, W. \& Proyer, R. T. (2009). 'Extending the study of gelotophobia: On gelotophiles and katagelasticists'. Humor: International Journal of Humor Research, 22, pp.183-212.

Ruch, W., Proyer, R. T., Harzer, C, Park, N., Peterson, C. \& Seligman, M. E. P. (2010). 'Adaptation and validation of the German version of the Values in Action Inventory of Strengths (VIA-IS) and the development of a peer-rating form'. Journal of Individual Differences, 31, pp.138-149.

Ruch, W., Rodden, F. A. \& Proyer, R. T. (2011). 'Humor and other positive interventions in medical and therapeutic settings.' in B. Kirkcaldy, (ed.), The art and science of health care: Psychology and human factors for practitioners, Göttingen: Hogrefe, pp. 277-294.

Seligman, M. E. P. (2002). Authentic happiness. New York, NY: Free Press.

Seligman, M. E. P. (2011). Flourish: A visionary new understanding of happiness and well-being. New York, NY: Free Press.

Seligman, M. E. P., Steen, T., Park, N. \& Peterson, C. (2005). 'Positive psychology progress: Empirical validation of interventions'. American Psychologist, 60, pp.410-421.

Sin, N. L. \& Lyubomirsky, S. (2009). 'Enhancing well-being and alleviating depressive symptoms with positive psychology interventions: A practice-friendly meta-analysis'. Journal of Clinical Psychology, 65, pp.467-487.

Singer, J. L, Singer D. G. \& Sherrod, L. R. (1980). 'A factor analytic study of preschooler's play behavior'. American Psychology Bulletin, 2, pp.143-156.

Staempfli, M. B. (2007). 'Adolescent playfulness, stress perception, coping and well-being'. Journal of Leisure Research, 39, pp.393-412.

Wiebe, D. J. \& Smith, T. W. (1997). 'Personality and health: Progress and problems in psychosomatics.' in R. Hogan, J. A. Johnson, \& S. R. Briggs, (eds.), Handbook of personality psychology, San Diego, CA: Academic Press, pp. 891-918.

Vollrath, M., Knoch, D. \& Cassano, L. (1999). 'Personality, risky health behaviour, and perceived susceptibility to health risks'. European Journal of Personality, 13, pp.39-50.

Wiesmann, U., Klein, A. \& Hannich, H.-J. (2011). ,Zur wahrgenommenen Förderlichkeit multipler Gesundheitsverhaltensweisen für die Gesundheitserhaltung [Perceived health maintenance outcomes of multiple health behaviors]'. Zeitschrift für Gesundheitspsychologie, 19, pp.134- 
145.

Wiesmann, U., Timm, A. \& Hannich, H.-J. (2003). Multiples Gesundheitsverhalten und Vulnerabilität im Geschlechtervergleich [A gender comparison of multiple health behavior and vulnerability]'. Zeitschrift für Gesundheitspsychologie, 11, pp.153-162.

Yu, P., Wu, J.-J., Chen, I. \& Lin, Y.-T. (2007). 'Is playfulness a benefit to work? Empirical evidence of professionals in Taiwan'. International Journal of Technology Measurement, 39, pp.412-429. 